\title{
Sistem Verifikasi Dokumen Menggunakan $Q R$-Code di Prodi Teknik Informatika Fakultas Ilmu Komputer Universitas Lancang Kuning
}

\author{
Jansihar Simorangkir ${ }^{\mathrm{a} 1}$, Mhd. Arief Hasan ${ }^{\mathrm{a} 2}$, Guntoro ${ }^{\mathrm{a} 3}$ \\ ${ }^{a}$ Teknik Informatika, Fakultas Ilmu Komputer, Universitas Lancang Kuning \\ Jl. Yos Sudarso KM. 8 Pekanbaru \\ ${ }^{1}$ jansiharsimorangkir@gmail.com \\ m.ariefeunilak.ac.id \\ ${ }^{3}$ guntoro@unilak.ac.id
}

\begin{abstract}
Abstrak
Sistem verifikasi dokumen adalah salah satu bentuk pencegahan pemalsuan dokumen, dimana setiap dokumen harus melalui verifikasi dan validasi untuk mengetahui keaslian dokumen. Pada Universitas Lancang Kuning terdapat beberapa fakultas salah satunya adalah fakultas Ilmu Komputer yang memiliki dua Prodi (Program Studi) yaitu Teknik Informatika dan Sistem infomasi. Dokumen - dokumen yang terdapat di Prodi Teknik Informatika belum memiliki sistem verifikasi atau validasi yang mana akan mengakibatkan terjadi praktik pemalsuan dokumen yang dapat merugikan mahasiswa, pihak Civitas Prodi Teknik Informatika, maupun Fakultas. Salah satu teknologi informasi yang dapat mengurangi pemalsuan dokumen adalah penggunaan QR Code (Quick Response Code) dalam mengidentifikasi maupun melakukan verfikasi. Pada perancangan sistem verifikasi dokumen ini menggunakan UML (Unified Modelling Language) untuk memodelkan dan merancang sistem yang akan dibangun. Permodelan yang digunakan adalah permodelan waterfall, dimana permodelan ini sebagai langkah - langkah pemecah suatu masalah agar mencapai suatu tujuan tertentu dalam pembuatan aplikasi, mulai dari tahap analisa sistem, design sistem, implementasi hingga pengujian sistem. Pada pengujian sistem menggunakan metode blackbox yang berfokus pada spesifikasi fungsional dari perangkat lunak. Hasil dari penelitian ini yaitu sistem vertifikasi dokumen berbasis web yang dapat membantu Fakultas Ilmu Komputer Universitas Lacang Kuning untuk melakukan verifikasi dokumen.
\end{abstract}

\section{Document Verification System Using QR-Code in the Informatic Engineering, Faculty of Computer Science, Universitas Lancang Kuning}

\begin{abstract}
Document verification system is one form of preventing document forgery, where each document must go through verification and validation to find out the authenticity of documents. At Lancang Kuning University there are several faculties, one of which is the Faculty of Computer Science which has two study programs (Study Programs), namely Informatics Engineering and Information Systems. The documents contained in the Informatics Engineering Study Program do not yet have a verification or validation system which will result in the practice of falsifying documents that can harm students, the Civitas Informatics Engineering Study Program, or the Faculty. One information technology that can reduce document forgery is the use of QR Code (Quick Response Code) in identifying and verifying. In designing the verification system this document uses UML (Unified Modeling Language) to model and design the system to be built. The model used is the waterfall model, where this model is a step - solving problem in order to achieve a certain goal in making applications, starting from the system analysis stage, system design, implementation to system testing. In testing the system using the blackbox method that focuses on the functional specifications of the software. The results of this study are webbased document vertification systems that can help the Faculty of Computer Science at Lacang Kuning University to verify documents.
\end{abstract}

Keywords: QR-Code, Verification, Documents 


\section{Pendahuluan}

Teknologi informasi membawa pengaruh yang sangat besar pada kehidupan manusia hampir di setiap bidang kehidupan. Dibalik berkembang pesatnya teknologi informasi terdapat sebuah sistem yang membuat sebuah perubahan dari era yang manualisasi ke era yang pastinya lebih komputerisasi [1]. Dengan adanya perkembangan yang ada pada bidang teknologi informasi kini ikut serta mempengaruhi Perguruan Tinggi dalam kegiatan pelayanan akademik [2]. Salah satunya bertujuan untuk meningkatkan taraf efektifitas dan efisiensi kerja [3].

Dengan berkembangnya teknologi informasi sering kali terjadi penyelewengan dokumen, terutama dokumen dokumen cetak [4]. Dokumen merupakan salah satu data yang sangat penting karena merupakan sumber informasi yang dibutuhkan baik individu, kelompok, organisasi, instansi maupun Negara [5]. Tanpa adanya dokumen, maka seseorang akan kehilangan data - data yang akan digunakan untuk keperluan dimasa mendatang [4]. Pemalsuan dokumen sangat mudah dilakukan oleh orang yang tidak bertanggung jawab dengan cara meniru bentuk serta isi dari suatu dokumen [6]. Salah satu teknologi informasi yang dapat mengurangi pemalsuan dokumen adalah penggunaan QR Code (Quick Response Code) dalam mengidentifikasi maupun melakukan verfikasi [7] [8].

Pada Universitas Lancang Kuning terdapat beberapa fakultas salah satunya adalah fakultas Ilmu Komputer yang memiliki dua Prodi (Program Studi) yaitu Teknik Informatika dan Sistem infomasi. Dokumen - dokumen yang terdapat di Prodi Teknik Informatika belum memiliki sistem verifikasi atau validasi yang mana akan mengakibatkan terjadi praktik pemalsuan dokumen yang dapat merugikan mahasiswa, pihak Civitas Prodi Teknik Informatika, maupun Fakultas. Untuk mengantisipasi terjadi pemalsuan dokumen, maka perlu dilakukan pengamanan dengan cara menyisipkan suatu objek pengenal, seperti nama pemilik, ID, ataupun tanda tangan yang dapat digunakan sebagai media untuk mencocok konten yang tertulis pada dokumen, yang kemudian akan disisipkan dan diproses sedemikian rupa menjadi sebuah kode yang akan diidentifikasi dan dicocokkan. Alasan menggunakan QR Code karena QR Code adalah suatu teknik yang mengubah data tertulis menjadi kode-kode 2 dimensi yang tercetak ke dalam suatu media. QR Code dipilih karena mampu menyimpan data berjenis Numerik atau angka, biner, alpanumerik, dan kanji/kana. QR Code juga memiliki tampilan lebih kecil daripada barcode, ini dikarenakan QR Code mampu menampung data secara horizontal dan vertikal [9]. QR Code juga tahan terhadap kerusakan hingga $30 \%$ tergantung ukuran dan atau versinya [10].

Diharapkan dengan adanya sistem ini, mahasiswa, dosen, dan berbagai elemen di Perguruan Tinggi Universitas Lancang Kuning terkhusus Fakultas Ilmu Komputer Program Studi Teknik Informatika dapat melakukan pengecekan dokumen yang dibuat secara online, dan ini akan lebih mengefisiensi waktu dalam pengecekan dan verfikasi dokumen.

\section{METODE}

Pada penelitian ini menggunakan metode waterfall dalam proses pengembangan perangkat lunak. Metode waterfall digunakan oleh seorang peneliti dengan cara menempuh hasil menggunakan langkah - langkah sebagai pemecah suatu masalah agar mencapai suatu tujuan tertentu. Adapun metode yang digunakan seperti terlihat pada gambar 1 .

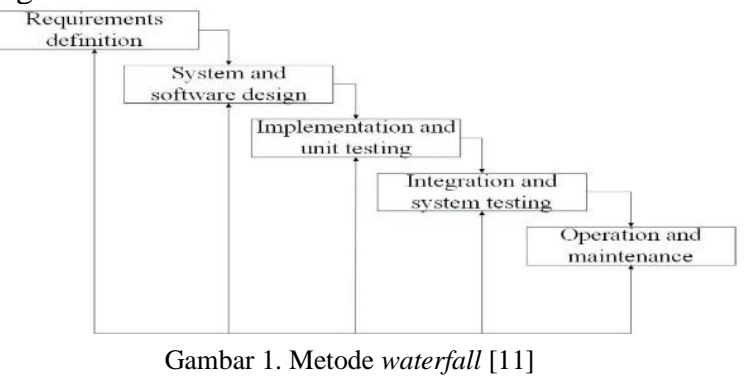

Pada prinsipnya, setiap tahapan di metode Waterfall menghasilkan satu atau lebih dokumen yang sudah disetujui ("ditandatangani") [12]. Tahap berikutnya tidak dapat dimulai sebelum tahapan sebelumnya selesai. Dalam tataran praktis, tahapan-tahapan tersebut saling tumpang tindih (overlap) dan memberikan informasi satu sama lain [13].

Permodelan ini melalui tahapan Requirement analysis melibatkan hasil konsultasi dengan tujuan pengguna dapat mendefenisikan secara rinci untuk spesifikasi sistem [14]. Tahapan Design untuk melakukan perancangan sistem baik itu perangkat lunak maupun perangkat keras [15]. Tahapan Implementation, disinilah perkembangan aktual sistem terjadi sesuai dengan spesifikasi desain, rangkaian program di bangun untuk merealisiasikan ke program lainnya. Tahap pengujian juga melibatkan verifikasi dan validasi untuk mengevaluasi apakah sistem sepenuhnya atau sebagaian memenuhi persyaratan pada sistem guna mendapatkan spesifikasi yang terbaik Selanjutnya system testing merupakan tahapan pengujian sistem apakah program sudah dapat memenuhi kebutuhan, Sebuah sistem atau beberapa sistem yang akan digabungkan menjadi satu program dan di uji apakah program tersebut sudah memenuhi kebutuhan pada perangkat lunak atau masih perlu perbaikan lagi, setelah validasi program berhasil di uji maka perangkat lunak dapat di kirim kepada customer. Dan tahap akhir operation and maintenance yaitu dimana melakukan hosting dan pemeliharaan sistem.

\section{HASIL DAN PEMBAHASAN}

Dalam membangun sistem verifikasi dokumen ini, perlu melakukan analisa sistem, usulan sistem baru yang dimodelkan menggunakan UML, serta Implementasi dimana tahapan membangun aplikasi sesuai dengan desain atau rancangan yang telah dibuat sebelumnya.

\section{A. Analisa Sistem}

Dalam melakukan analisis sistem, terlebih dahulu harus mengetahui dan memahami sistem. Untuk mengalisa sistem diperlukan data dari sistem untuk dianalisa. Data 
yang diperlukan adalah hal-hal yang diperlukan untuk definisi data.

\section{B. Usulan Sistem Baru}

Tujuan dari desain sistem yang baru ini adalah Merancang sistem verifikasi dokumen menggunakan QR Code di Prodi Teknik Informatika berbasis web. Alat bantu untuk merancang sistem verifikasi dokumen menggunakan Unifed Modeling Language (UML). Adapun hasil usulan sistem baru terlihat pada gambar 2, 3, dan 4 .

\section{1) Busines Proses Model}

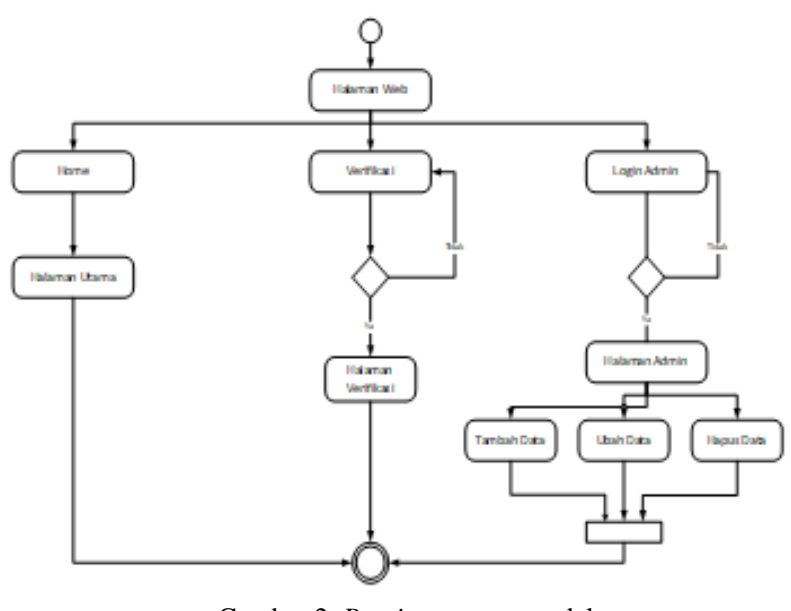

Gambar 2. Bussines proses model

\section{2) Usecase Diagram}

Usecase diagram menggambarkan secara ringkas siapa pengguna sistem dan hak akses terhadap sistem, dimana admin memiliki akses penuh, sementara user hanya memiliki akses membuka web dan melakukan verifikasi.

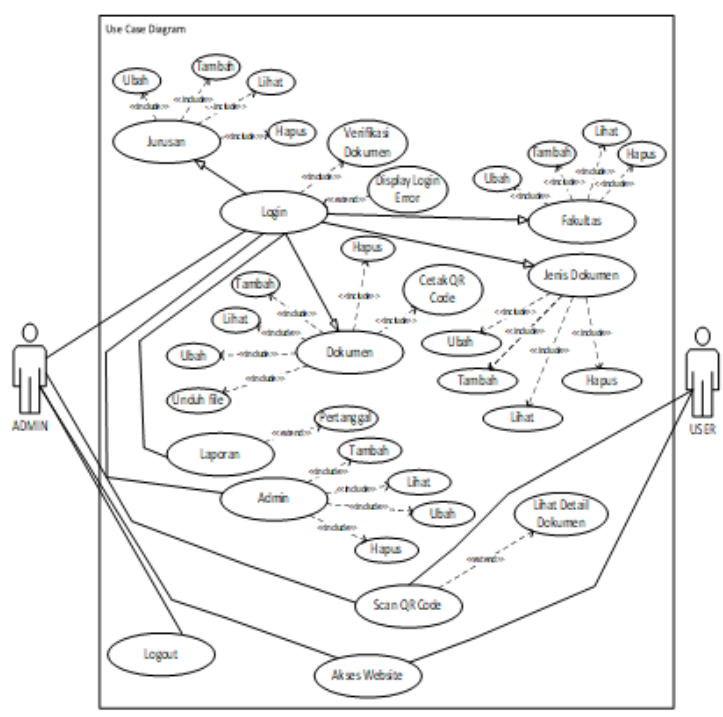

Gambar 3. Usecase diagram

\section{3) Class Diagram}

Class adalah sebuah spesifikasi yang jika diinstansikan menghasilkan sebuah objek dan merupakan inti dari pengembangan dan desain berorientasi objek. Class menggambarkan keadaan (attribut atau proses) suatu sistem, sekaligus menawarkan layanan untuk memanipulasi keadaan tersebut (metoda atau fungsi). Class Diagram menggambarkan struktur dan deskripsi calss, package dan objek beserta hubungan satu sama lain.

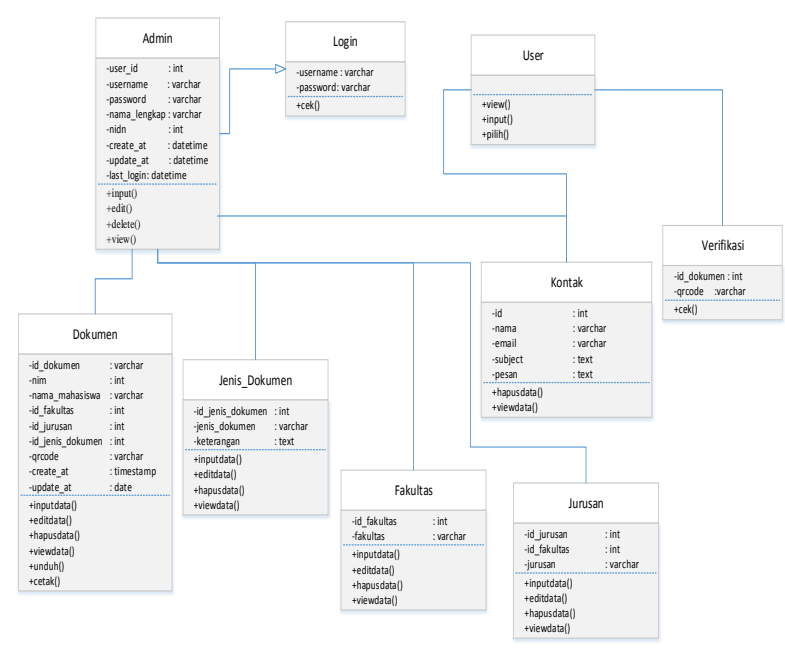

Gambar 4. Class diagram

\section{4) Deployment Diagram}

Deployment diagram yaitu menyediakan gambaran bagaimana sistem secara fisik dan terlihat. sistem yang terdiri dari node-node dimana setiap node tersebut diwakili dengan symbol atau sebuah kubus.

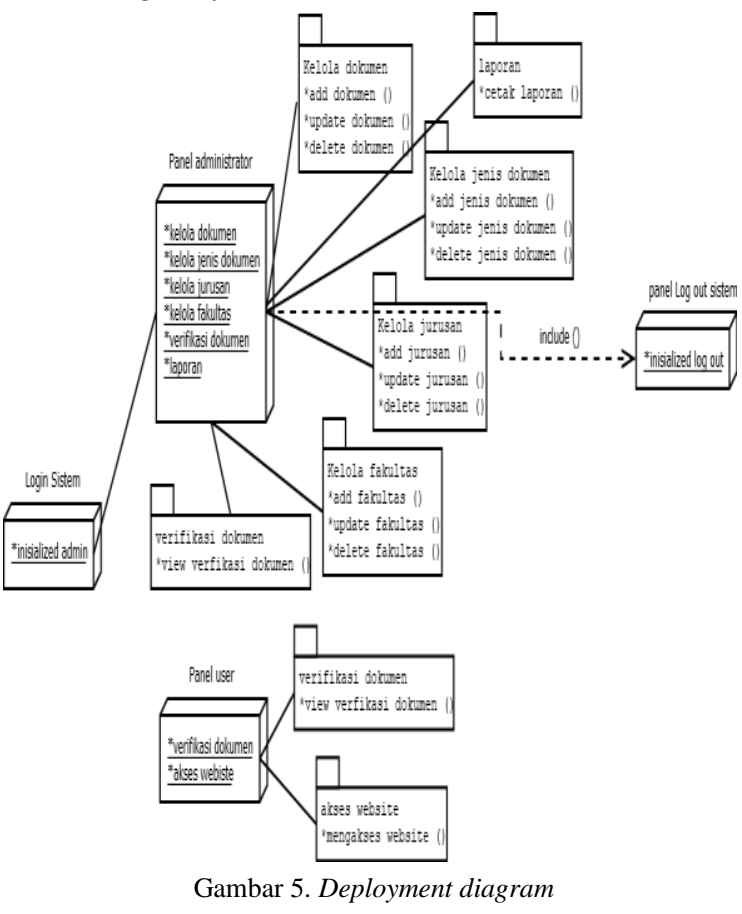

\section{Implementasi}

Pada tahapan ini pengembangan dari tahap desain sistem. Tahapan ini yang paling penting karena mengimplementasikan komponen dalam sistem yang telah di rancang sebelumnya.

1) Implementasi Login Admin: Halaman login untuk proses verifikasi masuk kedalam sistem. Gambar 6 adalah tampilan implementasi halaman login. 


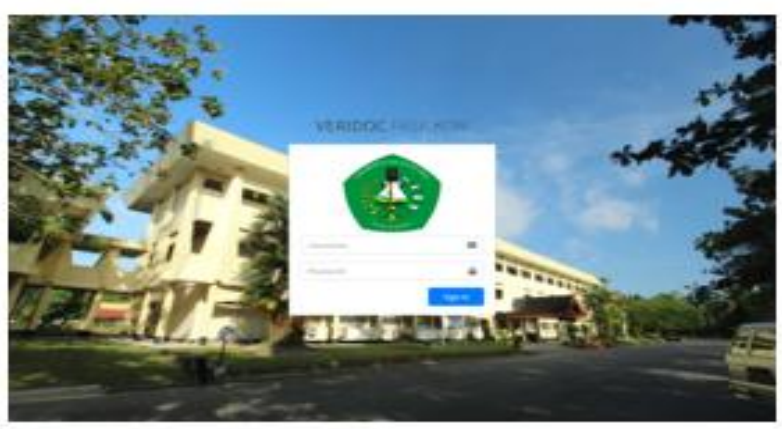

Gambar 6. Login admin

2) Implementasi Dashboard Administrator: Setelah melakukan login, maka administrator akan dialihkan ke Halaman dashboard administrator, seperti terlihat pada gambar 7.

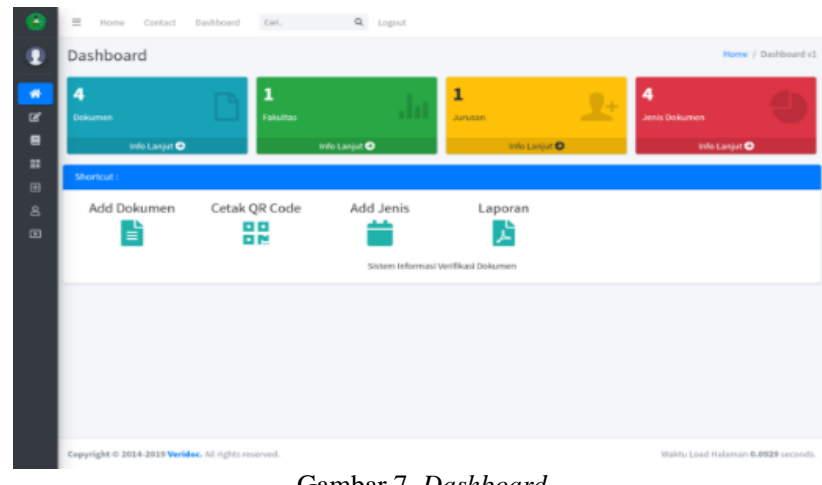

Gambar 7. Dashboard

3) Implementasi Data Dokumen: Setelah menekan tombol dokumen pada sidebar, maka administrator akan dialihkan ke halaman data dokumen. Adapun implementasi data dokumen seperti terlihat pada gambar 8 .
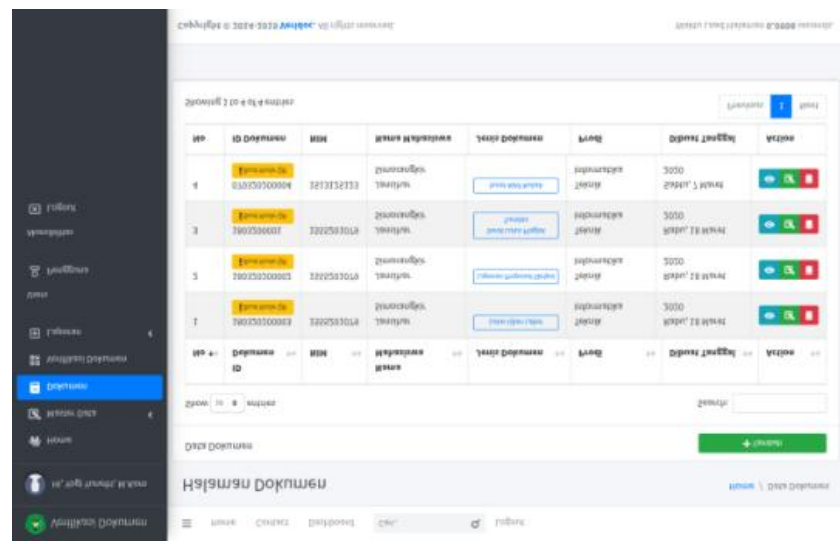

Gambar 8. Implementasi data

4) Implementasi Tambah Dokumen: Setelah menekan tombol tambah, maka administrator akan dialihkan ke halaman tambah dokumen. Pada gambar 9 merupakah form tambah dokumen
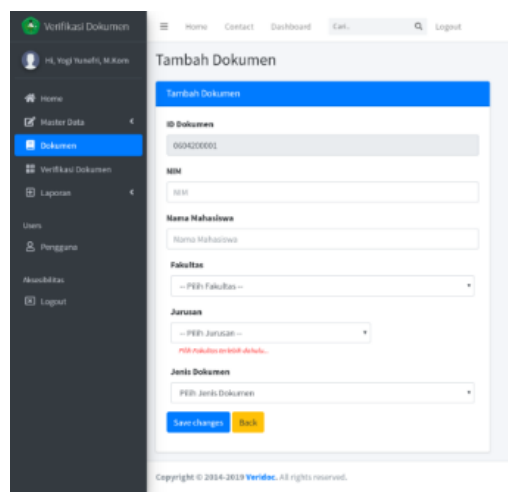

Gambar 9. Tambah dokumen

5) Implementasi Ubah Dokumen: Administrator akan melakukan ubah data, maka administrator akan menekan tombol edit pada salah satu data dokumen dan administrator akan dialihkan ke halaman edit dokumen. Pada gambar 10 adalah administrator dapat memperbaiki data yang dianggap salah.
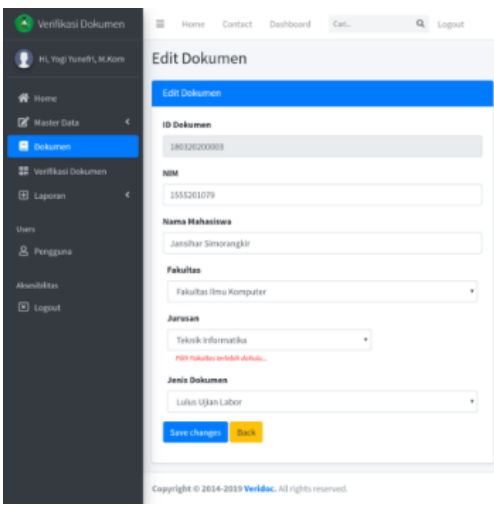

Gambar 10. Ubah dokumen

6) Implementasi Lihat QR Code Dokumen: Pada gambar 11 merupakah hasil pembuatan QR Code Dokumen.

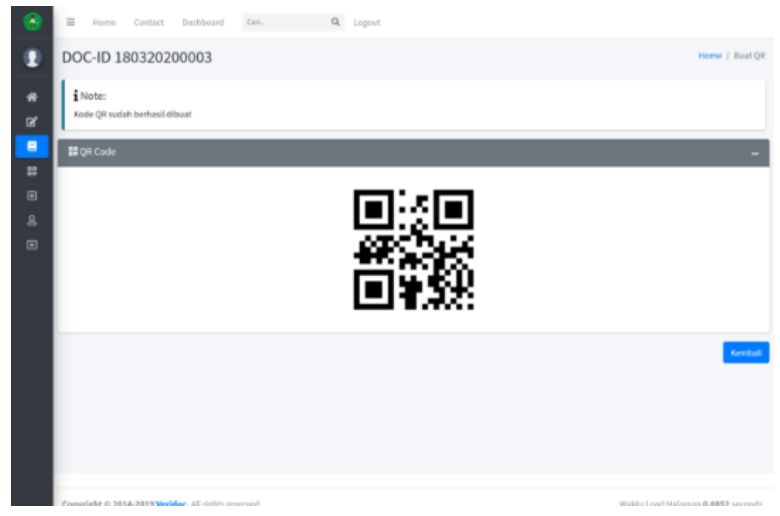

Gambar 11. QR code dokumen

7) Implementasi Lihat Dokumen: Pada gambar 12 merupakah tampilan untuk melihat dokumen, setelah discan dengan QR Code 

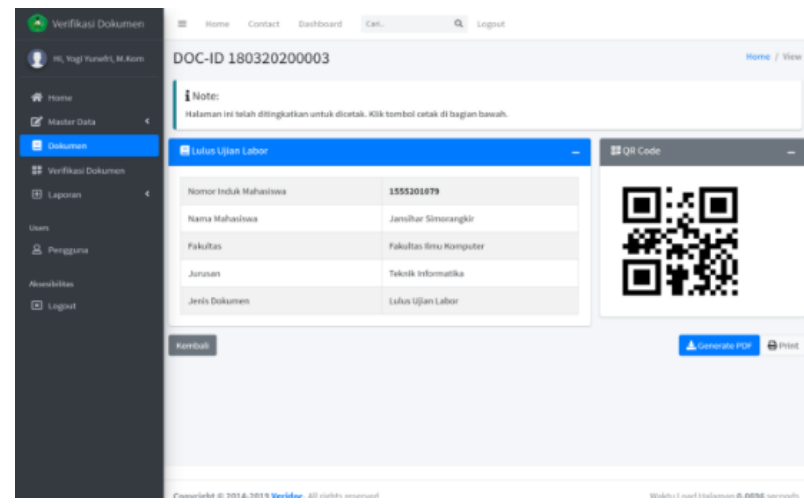

Gambar 12. Lihat dokumen

8) Implementasi Scanner Dokumen: Pada gambar 13 merupakan tampilan scanner dokumen. Admin dapat melakukan scanning dokumen, apakah terdapat di dalam sistem ataut tidak.

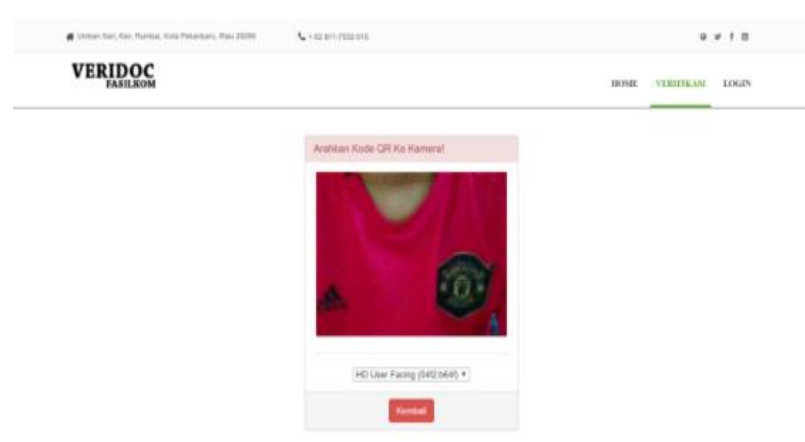

Gambar 13. Scanner dokumen

9) Implementasi Halaman Hasil Scanner Dokumen: Pada gambar 14 terdapat informasi hasil scan QR Code, jika hasil scanning berhasil, maka halaman ini akan menampilkan data.

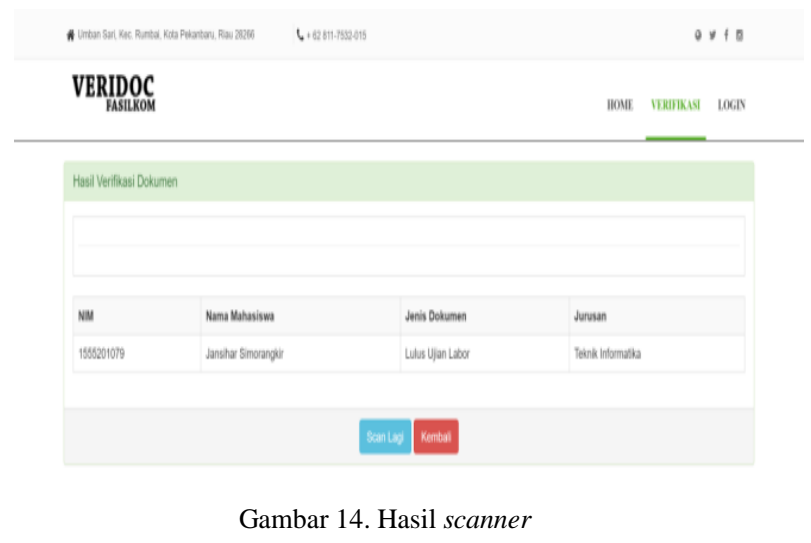

10) Implementasi Fakultas: Pada gambar 15 merupakan tampilan informasi fakultas. Admin dapat menambahkah, merubah, mendelete serta melihat fakultas.

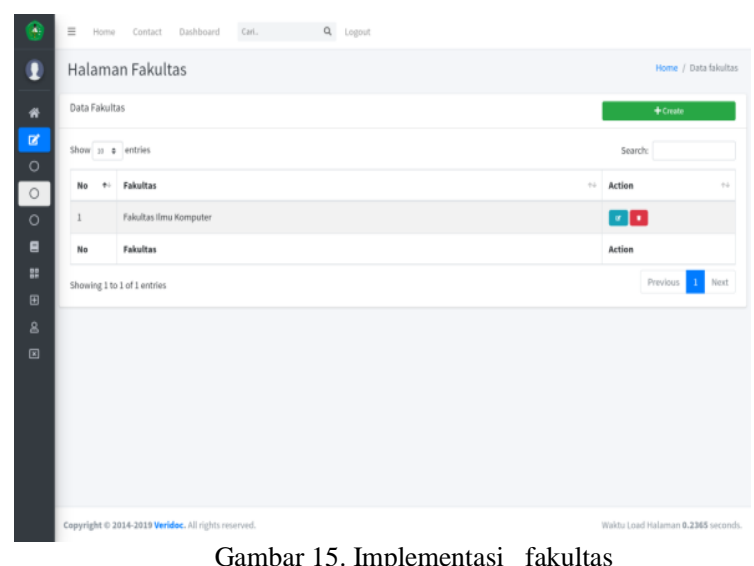

11) Implementasi Prodi: Pada gambar 10 merupakan tampilan informasi prodi. Admin dapat menambahkah, merubah, mendelete serta melihat prodi.

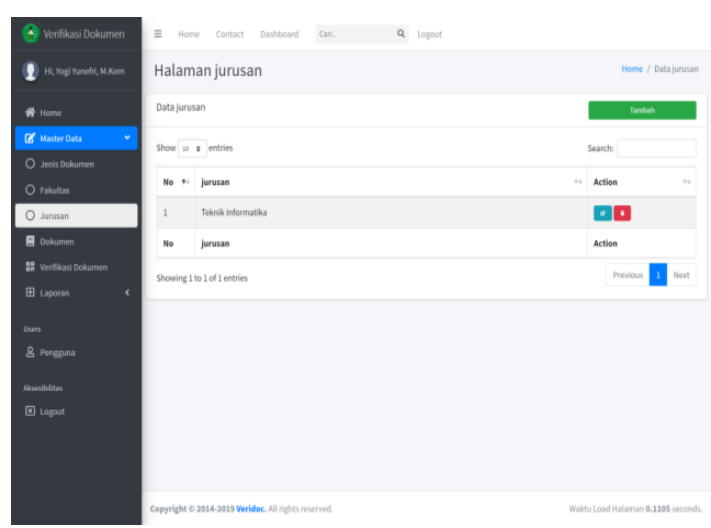

Gambar 16. Implementasi prodi

12) Implementasi Jenis Dokumen: Pada gambar 17, admin dapat melihat, menambah, menhapus jenis dokumen.

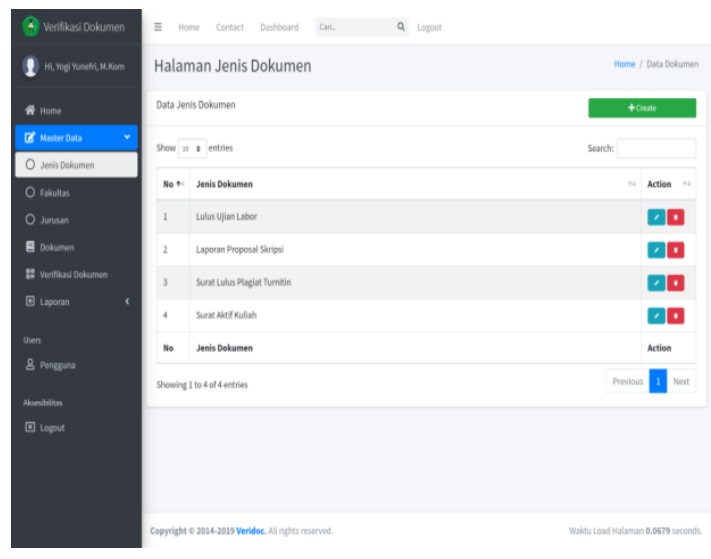

Gambar 17. Jenis dokumen

13) Implementasi Lihat Dokumen: Pada gambar 18 berfungsi untuk melihat dokumen yang telah terdaftar di sistem dan keterangan keaslian dari dokumen tersebut. 


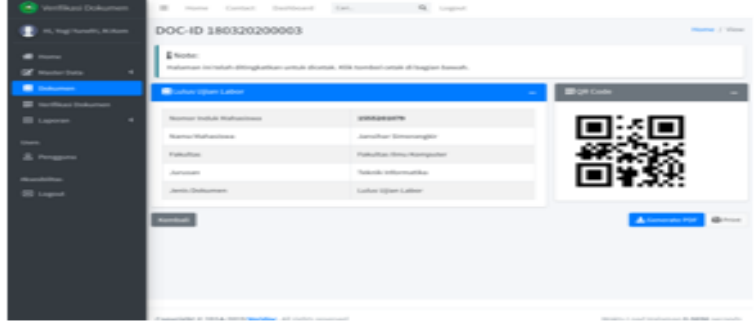

Gambar 17. Lihat dokumen

\section{Pengujian Sistem}

Pengujian pada sebuah program penting untuk dilakukan guna memeriksa semua kesalahan yang ada pada program tersebut agar tidak terjadi kerugian yang akan ditimbulkan dari kesalahan tersebut, sehingga sangat perlu untuk dilakukan pengujian untuk mengurangi terjadinya kesalahan yang merugikan tersebut. Pengujian dilakukan dengan dua metode yaitu pengujian Blackbox dan User Aceptance Test (UAT).

1) Pengujian Blackbox: Black Box merupakan pengujian yang berfokus pada spesifikasi fungsional dari perangkat lunak. Tester akan mengkondisikan kumpulan kondisi dari aplikasi dan melakukan pengetesan pada spesifikasi (fungsional program). Adapun hasil pengujiannya seperti terlihat pada tabel 1 .

TABEL I.

PENGUJIAN BLACKBOX

\begin{tabular}{|c|c|c|}
\hline Data Masukan & $\begin{array}{c}\text { Hasil yang } \\
\text { Diharapkan }\end{array}$ & Kesimpulan \\
\hline $\begin{array}{l}\text { Mengakses Halaman } \\
\text { Utama }\end{array}$ & $\begin{array}{l}\text { menampilkan } \\
\text { halaman utama } \\
\text { website dan terdapat } \\
\text { menu home, verfikasi } \\
\text { dan login }\end{array}$ & Berhasil \\
\hline $\begin{array}{l}\text { Mengakses Halaman } \\
\text { Login Administrator }\end{array}$ & $\begin{array}{l}\text { Menampilkan } \\
\text { halaman berisi form } \\
\text { yang harus diisi yaitu } \\
\text { username } \\
\text { password. }\end{array}$ & Berhasil \\
\hline $\begin{array}{lr}\text { Menu } & \text { Manajemen } \\
\text { Jenis } & \text { Dokumen } \\
\text { Administrator }\end{array}$ & $\begin{array}{l}\text { Menampilkan sub } \\
\text { menu dari master data }\end{array}$ & Berhasil \\
\hline $\begin{array}{l}\text { Menu Manajemen } \\
\text { Fakultas } \\
\text { Administrator }\end{array}$ & $\begin{array}{l}\text { Menampilkan sub } \\
\text { menu dari master data }\end{array}$ & Berhasil \\
\hline $\begin{array}{l}\text { Menu Manajemen } \\
\text { Prodi Administrator }\end{array}$ & $\begin{array}{l}\text { Menampilkan sub } \\
\text { menu dari master data }\end{array}$ & Berhasil \\
\hline $\begin{array}{l}\text { Menu Manajemen } \\
\text { Dokumen } \\
\text { Administrator }\end{array}$ & $\begin{array}{l}\text { Menampilkan } \\
\text { manajemen jenis } \\
\text { dokumen }\end{array}$ & Berhasil \\
\hline $\begin{array}{ll}\text { Menu } & \text { Verifikasi } \\
\text { Dokumen } & \end{array}$ & $\begin{array}{l}\text { Menampilkan form } \\
\text { verifikasi dokumen }\end{array}$ & Berhasil \\
\hline $\begin{array}{l}\text { Menu Manajemen } \\
\text { Pengguna } \\
\text { Administrator }\end{array}$ & $\begin{array}{l}\text { Menampilkan } \\
\text { halaman manajemen } \\
\text { pengguna }\end{array}$ & Berhasil \\
\hline $\begin{array}{l}\text { Menu Manajemen } \\
\text { Laporan } \\
\text { Administrator }\end{array}$ & $\begin{array}{l}\text { Menampilkan } \\
\text { Laporan }\end{array}$ & Berhasil \\
\hline $\begin{array}{l}\text { Menu Logout } \\
\text { Administrator }\end{array}$ & $\begin{array}{l}\text { Menampilkan } \\
\text { halaman login }\end{array}$ & Berhasil \\
\hline
\end{tabular}

2) Pengujian UAT (User Aceptance Test): Pengujian UAT adalah suatu proses pengujian oleh pengguna yang dimaksudkan untuk menghasilkan dokumen yang dijadikan bukti bahwa sistem yang dikembangkan dapat diterima atau tidaknya oleh pengguna, apabila hasil pengujian sudah bisa dianggap memenui kebutuhan dari pengguna maka aplikasi dapat diterapkan.

Pengujian dengan UAT dilakukan dengan mengajukan beberapa pertanyaan terhadap kepada Ketua dan Sekretaris Prodi Teknik Informatika, Fakultas Ilmu Komputer, Universitas Lancang Kuning. Hasil user acceptance test dinilai dengan 5 kategori, yaitu SS (Sangat Sesuai), S (Sesuai), KS (Kurang Sesuai), TS (Tidak Sesuai) dan TJ (Tidak Jawab). Adapun hasil pengujiannya terlihat pada tabel 2 .

TABEL II.

PENGUJIAN UAT (User Acceptance Test)

\begin{tabular}{|c|c|c|c|c|c|c|}
\hline No & Pertanyaan & SS & $\mathbf{S}$ & KS & TS & TJ \\
\hline 1 & $\begin{array}{l}\text { Apakah tampilan sistem } \\
\text { verifikasi ini menarik? }\end{array}$ & - & 2 & - & - & - \\
\hline 2 & $\begin{array}{l}\text { Apakah tampilan menu } \\
\text { sistem ini sesuai yang } \\
\text { diharapkan? }\end{array}$ & 1 & 1 & - & - & - \\
\hline 3 & $\begin{array}{l}\text { Apakah tampilan } \\
\text { manajemen dokumen } \\
\text { mudah digunakan? }\end{array}$ & 1 & 1 & - & - & - \\
\hline 4 & $\begin{array}{l}\text { Apakah tampilan } \\
\text { manajemen fakultas } \\
\text { mudah digunakan? }\end{array}$ & 2 & - & - & - & - \\
\hline 5 & $\begin{array}{l}\text { Apakah menu } \\
\text { manajemen prodi sesuai } \\
\text { yang diharapkan? }\end{array}$ & 2 & - & - & - & - \\
\hline 6 & $\begin{array}{l}\text { Apakah proses verifikasi } \\
\text { dokumen sesuai yang } \\
\text { diharapkan? }\end{array}$ & - & 2 & - & - & - \\
\hline 7 & $\begin{array}{l}\text { Apakah manajemen } \\
\text { laporan sesuai yang } \\
\text { diharapkan? }\end{array}$ & - & 2 & - & - & - \\
\hline 8 & $\begin{array}{l}\text { Apakah menu logout bisa } \\
\text { digunakan }\end{array}$ & 2 & - & - & - & - \\
\hline
\end{tabular}

\section{KESIMPULAN}

Berdasarkan hasil implementasi dan pengujian maka dapat disimpulkan yaitu: (1) Dengan adanya Aplikasi ini, dapat membantu Prodi Teknik Informatika Fakultas Ilmu Komputer Universitas Lacang Kuning untuk melakukan verifikasi dokumen. (2) Menyediakan data dan informasi berbasis web agar data dapat diakses dengan mudah oleh pihak Prodi. (3) Mengurangi adanya pemalsuan dokumen di prodi Teknik Informatika Fakultas Ilmu Komputer Universitas Lancang Kuning. (4) Berdasarkan hasil pengujian blackbox, aplikasi bisa digunakan sesuai dengan yang diharapkan. (5) berdasarkan hasil pengujian menggunakan uat (user aceptance test), aplikasi menarik serta mudah digunakan sesuai dengan yang diharapkan, dengan nilai rata-rata $95 \%$.

\section{DAFTAR PUSTAKA}

[1] Z. Effendi and Murinto, "Aplikasi Multimedia Sebagai Media Informasi Pada Pengenalan Monumen Yogya Kembali Yogyakarta," J. Sarj. Tek. Inform., vol. 2, no. 1, pp. 342-353, 2014

[2] S. Jamaluddin, "Implementasi Pemanfaatan Aplikasi QR Code dalam Proses Pembelajaran PPKn,” vol. 8, no. 3, pp. 195-201, 
2020.

[3] R. Focardi, F. L. Luccio, and H. A. M. Wahsheh, "Usable security for QR code," J. Inf. Secur. Appl., vol. 48, p. 102369, 2019.

[4] Q. Aini, Y. I. Graha, and S. R. Zuliana, "Penerapan Absensi QRCode Mahasiswa Bimbingan Belajar pada Website berbasis YII Framework Application Student Attendance QRCode in Guidance Learn to Website Based on Yii Framework," J. Ilm. SISFOTENIKA, vol. 7, no. 2, pp. 207-218, 2017.

[5] N. Rubiati and S. W. Harahap, "Aplikasi Absensi Siswa Menggunakan Qr Code Dengan Bahasa Pemrograman Php Di Smkit Zunurain Aqila Zahra Di Pelintung," I N F O R M a T I Ka, vol. 11, no. 1, p. 62, 2019.

[6] K. M. Wibowo, K. Indra, and J. Jumadi, "Sistem Informasi Geografis (SIG) Menentukan Lokasi Pertambangan Batu Bara di Provinsi Bengkulu Berbasis Website,” J. Media Infotama, vol. 11, no. 1, pp. 51-60, 2015.

[7] E. Ardhianto and N. Wakhidah, "PENGEMBANGAN METODE OTENTIKASI KEASLIAN IJASAH DENGAN MEMANFAATKAN GAMBAR QR CODE," Pengemb. Metod. OTENTIKASI KEASLIAN IJASAH DENGAN MEMANFAATKAN GAMBAR OR CODE Eka, vol. 13, no. 2, pp. 35-41, 2016.

[8] M. N. Fu'ad, M. Kholil, and S. I. Wardhani, "Rancang Bangun Aplikasi QR Code Berbasis Android Pada Perpustakaan Akademi Komunitas Negeri Putra Sang Fajar Blitar," VOCATECH Vocat. Educ. Technol. J., vol. 1, no. 1, pp. 5-12, 2019.

[9] A. R. Fauzi and K. Kunci, "Perangkat Lunak Presensi Prodi Telekomunikasi Menggunakan Aplikasi QR Code di Smartphone Android," pp. 26-27, 2020.

[10] U. Rahmalisa, Y. Irawan, and R. Wahyuni, "APLIKASI ABSENSI GURU PADA SEKOLAH BERBASIS ANDROID ( STUDI KASUS : SMP NEGERI 4 BATANG GANSAL ) RJoCS Aplikasi Absensi Guru pada Sekolah Berbasis Android dengan Keamanan QR Code RJoCS," vol. 06, no. 02, pp. 135-144, 2020.

[11] G. Wira Astawa, I. G. L. Agung Raditya Putra, and I. G. P. Krisna Juliharta, "Aplikasi Android Lukisan Wayang Kamasan Menggunakan Qr Code Sebagai Media Promosi Interaktif ( Studi Kasus: Startup Way'K)," Infotronik J. Teknol. Inf. dan Elektron., vol. 4, no. 1, p. 1, 2019

[12] M. D. Setiadi and N. Rosmawarni, "PERANCANGAN APLIKASI QR CODE SEBAGAI MEDIA INFORMASI PENGENALAN SATWA KEBUN BINATANG BERBASIS WEBSITE," J. Rekayasa Inf., vol. 9, no. 1, pp. 44-52, 2020.

[13] Guntoro, B. Hamuddin, and B. Febriadi, "RANCANG BANGUN PORTAL INTERNATIONAL CONFERENCE ON ENVIRONMENT AND TECHNOLOGY (IceTech) UNIVERSITAS LANCANG KUNING," JIPI (Jurnal Ilm. Penelit. dan Pembelajaran Inform., vol. 04, no. 01, pp. 28-35, 2019.

[14] Mustakim, Guntoro, U. Khaira, W. Kalengkongan, and Hidayat, "PERANCANGAN SISTEM INFORMASI PENDAFTARAN SEMINAR MAHASISWA PASCASARJANA INSTITUT PERTANIAN BOGOR," J. Rekayasa Dan Manaj. Sist. Inf., vol. 1, no. 2, pp. 6-14, 2015.

[15] Guntoro and M. Fikri, "Perancangan Aplikasi Single Sign-On Menggunakan Otentikasi Gambar," J. Teknol. Inf. Komun. Digit. Zo., vol. 7, no. 2, pp. 1-10, 2016. 